\title{
Cyanobacteria in Inland Waters: Remote Sensing
}

\author{
Lin Li (https://orcid.org/0000-0002-3422-7348) \\ Department of Earth Sciences \\ Indiana University $\sim$ Purdue University Indianapolis \\ Indianapolis, IN 46202, USA
}

\section{Introduction}

Cyanobacterial (CYB) blooms are one of the most important issues concerning environmental agencies, water authorities and public health organizations. Cyanobacteria in surface water systems pose a health concern for humans, livestock, and native wildlife across the globe. Ecological effects of CYB blooms include changes in phytoplankton community structure, fish community structures and lake anoxia. Nuisance and harmful CYB blooms in water bodies can result in a series of social-economic issues such as aesthetic degradation of lakes and reservoirs due to the presence of surface scums and earthy smells, recreational degradation due to hypolimnetic anoxia and kills of desirable sport fish, and human health impairment due to the production of toxins such as anatoxins, microcystins and cylindrospermopsins. The occurrence of toxic CYB blooms is of great concern due to embedded implications for alternated biodiversity, public health, and for overall ecosystem health of inland waters. It is critical for water resource managers and policy makers to monitor toxic CYB blooms effectively.

Monitoring CYB blooms via in situ water sampling is time and labor intensive, and is otherwise limited to infrequent water sample collection. To overcome this limitation, remote sensing has been used in estimating and mapping CYB blooms, and three remote sensing algorithms, namely

This is the author's manuscript of the article published in final edited form as:

Li, L. (2020). Cyanobacteria in Inland Waters: Remote Sensing. In Y. Wang (Ed.), Fresh Water and Watersheds. CRC Press. 
empirical, analytical, semi-analytical, have been proposed to quantify phycocyanin (PC), an accessory pigment unique to CYB blooms in inland waters, as well as chlorophyll-a (Chl-a), a primary CYB pigment. The empirical approach aims at establishing a statistical relationship between spectral variables (e.g. reflectance, reflectance ratio or derivative) and the CYB pigments [1-12]. However, the performance of varying empirical approaches is dataset dependent because of the variation of imaging and water conditions [e.g.,13-14]. The semi-analytical approach to quantifying CYB blooms utilizes the correlation between remote sending reflectance and water inherent optical properties (IOPs), which are referred to as the total absorption $(a)$ and backscattering $\left(b_{b}\right)$ of optically active constituents (OACs): phytoplankton, color dissolved organic matter (CDOM), and non-algal particle (NAP). Quantification of CYB concentration via the semianalytical approach is primarily achieved by first isolating the CYB absorption signal from the total OACs' absorption derived from remote sending reflectance, then removing the interference of overlapping Chl-a absorption from CYB absorption, and finally deriving PC concentrations from the remaining CYB absorption spectra. The semi-empirical approach focuses on analyzing the relationship between the CYB pigments and one or some spectral indices with the latter being parameterized by the IOPs of the relevant OACs. Insightful reviews of these PC estimation algorithms were given by Matthews et al. [15], Li and Song [16] and Yan et al. [17].

Over the past several years, a quite few literatures have been published to compare or assess various PC remote sensing algorithms when applied to different inland waters around the world, but the performance of a specific PC algorithm is inconsistent. Therefore, it is necessary to revisit several typical PC algorithms to examine their assumptions and suitability for different inland waters. Beside this main goal, these PC algorithms are assessed for their performance accuracy, 
ability for removal of the non-PC constituent interference, as well as their adaptability for different sensors. At last, scientifically important investigations to develop PC remote sensing algorithms in future are recommended.

\section{Spectral Characteristics of Inland Waters}

Algae contain colored pigments and show characteristic spectral features. Error! Reference source not found. shows in situ reflectance spectra of Eagle Creek reservoir measured in August of 2004. The spectral signature signifying the presence of algal pigments in the water includes (a) and (b) low reflectance at 440 and $500 \mathrm{~nm}$ resulting from algal chlorophyll and carotenoid, respectively $[18,19]$; (c) maximum reflectance between 560 and $570 \mathrm{~nm}$ due to the lack of absorption by algal chlorophyll, thus giving algae a green color to our eyes [20]; (d) a strong PC absorption at $620 \mathrm{~nm}$ unique to cyanobacteria due to PC absorbing primarily green and red light [20-21]; (e) a weak reflection at $640 \mathrm{~nm}$ ascribed to backscattering from dissolved organic matter or fluorescence of accessory pigment [21]; (f) strong Chl-a absorption at about $675 \mathrm{~nm}$ [18-19]; (g) strong reflectance peak around 690-700 nm caused by an interaction of algal-cell scattering and a combined effect of pigment and water absorption [18-21]; (h) a weak reflectance peak at about $810 \mathrm{~nm}$ likely due to backscattering from algal cells combined with the general absorption of near infrared in clear water [18-19]. These spectral characteristics of pigments and other water constituents provide a physical basis for quantifying the concentrations of cyanobacteria using remote sensing.

Insert Figure 1 here 


\section{Basic Radiative Transfer Equation}

Remote sensing reflectance above water surface $\left(R_{r s}(\lambda)\right)$ is a function of two IOP variables a $(\lambda)$ and $b_{b}(\lambda)$ and the function can be written as Equation 1 [22]:

$$
R_{r s}(\lambda)=\frac{f(\lambda)}{Q(\lambda)} \times \frac{b_{b}(\lambda)}{a(\lambda)+b_{b}(\lambda)}
$$

where $f(\lambda)$ describes the sensitivity of the reflectance to variations in the solar zenith angle, and $\mathrm{Q}(\lambda)$ is the bidirectional properties of the reflectance. For inland turbid waters, $a(\lambda)=a_{w}(\lambda)+$ $a^{*}{ }_{c h l}(\lambda)[\mathrm{CHL}]+a_{p c}^{*}(\lambda)[\mathrm{PC}]+a^{*}{ }_{N A P}(\lambda)[\mathrm{NAP}]+a^{*}{ }_{C D O M}(\lambda)[\mathrm{CDOM}]$ denotes total absorption coefficient of four water substances in the water column at a given wavelength, each term on the right side of this equation is the bulk absorption of the corresponding constituent which is defined as the product of the specific absorption coefficient (e.g., $\left.a^{*}{ }_{c h l}(\lambda)\right)$ of a constituent and concentration of that constituent (e.g., [CHL]). $b_{b}(\lambda)$ represents the total backscattering coefficient $\left(\mathrm{m}^{-1}\right)$ of OACs and water, and can be described as a linear combination of OACs' bulk backscattering coefficient, each of which is the product of the specific scattering coefficient (e.g., $\left.b_{b, p h y}^{*}(\lambda)\right)$ and concentration of that constituent (e.g., $\left.[\mathrm{Chl}-\mathrm{a}]\right)$. Furthermore, $\mathrm{f}(\lambda)$ and $\mathrm{Q}(\lambda)$ are

often assumed to be weakly dependent on wavelength [23-24]. This assumption is significant because a reflectance band ratio $(\mathrm{BR})$ can then be written as:

$$
\frac{R_{r s}\left(\lambda_{1}\right)}{R_{r s}\left(\lambda_{2}\right)}=\frac{b_{b}\left(\lambda_{1}\right)\left[a\left(\lambda_{2}\right)+b_{b}\left(\lambda_{2}\right)\right]}{b_{b}\left(\lambda_{2}\right)\left[a\left(\lambda_{1}\right)+b_{b}\left(\lambda_{1}\right)\right]}
$$

$\mathrm{A} B \mathrm{BR}$ as shown by Equation 2 is important for developing most $\mathrm{PC}$ algorithms which are listed in Table 1 and described below. Table 2 lists the symbols and acronyms which are used to describe the models. 


\section{Empirical Algorithms for PC Estimation}

Empirical algorithms for estimation of PC are commonly established based on its absorption feature around $620 \mathrm{~nm}$. Table 3 shows a summary of typical empirical algorithms. The simplest empirical algorithm in this group is the reflectance ratio of a near infrared wavelength to $620 \mathrm{~nm}$. Schalles and Yacobi [8] proposed to use the ratio of radiance reflectance at $650 \mathrm{~nm}$ to that at 620 $\mathrm{nm}\left(B R_{650 / 620}\right)$, and obtained an $\mathrm{R}^{2}$ of 0.612 when applied to in situ reflectance data measured by a portable Ocean Optics ST1000 spectraradiometer from Sept. 1994 to Jul. 1998 for Carter Lake, Nebraska, USA. The strong performance of this band ratio can be attributed to the dominance of cyanobacteria indicated by the range of PC concentrations $(10-530 \mu \mathrm{g} / \mathrm{L})$ and strong correlation of PC to Chl-a [8]. Hunter et al. [25] proposed a $\log _{10}$-transformed ratio of radiance at $710 \mathrm{~nm}$ to that at $620 \mathrm{~nm}\left(B R_{710 / 620}\right)$ and obtained an $\mathrm{R}^{2}$ of 0.95 when applied to time-series images acquired by the Compact Airborne Spectrographic Imager (CASI-2) over the shallow eutrophic waters of Barton Broad, UK to monitor diurnal changes in the spatial distribution of the potentially toxic cyanobacterium Microcystis aeruginosa with a PC range of $36-139 \mu \mathrm{g} / \mathrm{L}(\mathrm{N}=13)$. Li et al. [26] examined the performance of $B R_{650 / 620}$ and $B R_{710 / 620}$ in the estimation of PC concentrations with the Airborne Imaging Spectrometer for Application (AISA) image spectra of Geist Reservoir, Indiana, USA (PC: 25 to $185 \mu \mathrm{g} / \mathrm{L}$ ), and showed weak relationships of the two ratios to PC concentration ranging from 25 to $185 \mu \mathrm{g} / \mathrm{L}$ as a result of the effects of Chl-a and suspended sediment. Mishra et al. [27] observed the performance of $B R_{700 / 600}\left(\mathrm{R}^{2}=0.97\right)$ was superior to reflectance ratios $B R_{650 / 620}\left(\mathrm{R}^{2}=0.71\right)$ and $B R_{710 / 620}\left(\mathrm{R}^{2}=0.88\right)$ in the estimation of $\mathrm{PC}$ concentrations (506 - 273883 cells/L) with lab measured USB 4000 radiometer (Ocean Optics, Inc., Dunedin, FL, USA) spectra of cultured cyanobacterial species Synechocystis and Anabaena, and concluded that the strongest performance of $B R_{700 / 600}$ was due to its insusceptibility to varying 
Chl- $a$ concentrations while the poor performance of $B R_{650 / 620}$ and $B R_{710 / 620}$ resulted from the effect of Chl-a on the reflectance at $620 \mathrm{~nm}$. Ogashawara et al. [28] evaluated the accuracy and sensitivity of $B R_{650 / 620}, B R_{710 / 620}, B R_{700 / 600}, B R_{709 / 600}, B R_{724 / 600}$ for retrieval of PC concentrations from the reflectance spectra measured by the RAMSES hyperspectral radiometers (TriOS GmbH, Oldenburg, Germany) in Funil Reservoir, Brazil and the spectra measured with Ocean Optics spectroradiometers (Ocean Optics Inc., Dunedin, FL, USA) in catfish ponds, USA. In terms of $\mathrm{R}^{2}$ from high to low, these ratios were ranked as $B R_{709 / 600}, B R_{700 / 600}, B R_{710 / 620}, B R_{650 / 620}, B R_{724 / 600}$ for the Funil dataset (PC: $9-35 \mu \mathrm{g} / \mathrm{L}$ ), $B R_{700 / 600}, B R_{724 / 600}, B R_{650 / 620}, B R_{709 / 600}, B R_{710 / 620}$ for the catfish ponds (PC: $68-857 \mu \mathrm{g} / \mathrm{L}$ ), and $B R_{700 / 600}, B R_{724 / 600}, B R_{650 / 620}, B R_{710 / 620}, B R_{709 / 600}$. These band ratio results indicate the dependence of their performance on datasets for estimating PC concentration [29].

A midpoint reflectance baseline index (MRBI) using bands 600,624 , and $648 \mathrm{~nm}$ was proposed to describe the difference between reflectance $R_{r s}$ at $624 \mathrm{~nm}$ and the reflectance midpoint for bands 600 and $648 \mathrm{~nm}$ [3]. This index gave rise to a strong relationship $\left(\mathrm{R}^{2}=0.99\right)$ to PC measurements for the dataset collected from 9 shallow eutrophic lakes in the central western part of the Netherlands, but the application of MRBI to other datasets has a mixed success. For example, $\mathrm{Li}$ et at al. [26] reported a stronger performance of the $M R B I$ than $B R_{650 / 620}$ and $B R_{710 / 620}$ with the AISA image spectra, but an inferior PC estimation relative to $B R_{650 / 620}$ was observed with the radiance reflectance spectra collected from Carter Lake [8], and relative to all the ratios examined by Ogashawara et al. [28] with the Funil dataset. Explanation for these inconsistent results is not straightforward, but the relationship $a_{p c}(620)=M R B I /\left(\frac{R_{r s}(\lambda)-M R B I}{a(\lambda)+b_{b}(\lambda)}\right)$ can be derived from 
equations 5.13a-c in [3], which illustrates the effects of both the reflectance and the total light extinction $\left(a(\lambda)+b_{b}(\lambda)\right)$ at $620 \mathrm{~nm}$ on the correlation between $M R B I$ and PC concentration.

Wynne et al. [30] developed a spectral shape algorithm (SSA) and applied to the MEdium Resolution Imaging Spectrometer (MERIS) data to identify cyanobacteria blooms in Bear Lake, Michigan, USA. It is interesting to note that the MRBI is a special case of $S S A$ for a set of three evenly spaced wavelengths. Unlike other empirical methods, this SSA does not rely on PC absorption around $620 \mathrm{~nm}$, instead uses the Chl-a fluorescence at $681 \mathrm{~nm}$ to construct second derivatives with reflectance at wavelengths at 665 and $709 \mathrm{~nm}$ based on the difference of the fluorescence peak between CYB (weak fluorescence) and non-CYB species (strong fluorescence). The SSA was later adjusted for MODIS bands 678,667 , and $748 \mathrm{~nm}$ to monitor cyanobacterial blooms in Lake Erie [31-32], but Wynne et al. [31] pointed out that a weak Chl-a fluorescence signal could be due to other processes instead of the CYB presence.

Qi et al. [33] proposed a PC index $(P C I)$ using the spectral shape for the derivatives at 550,620, and $665 \mathrm{~nm}$ to estimate PC concentrations in Lake Taihu in China. Despite its mathematical equivalent to SSA and MRBI, PCI is expected to be more reliable than SSA for estimating PC concentration, and more suitable than $M R B I$ for satellite multispectral sensors. However, like MRBI and other empirical models, PCI's performance can be affected by sediment, other phytoplankton assemblage, and a strong absorption of water between $550 \mathrm{~nm}$ and $620 \mathrm{~nm}$ [34]. These drawbacks are more or less addressed by the semi-empirical algorithms to be discussed below. 


\section{Semi-Empirical Algorithms for PC Estimation}

Table 4 shows PC algorithms in this group including the models established using three bands [25, 35-36], double three bands and the absorption baseline [37], four bands [38], and four bands and reflectance baseline [39]. For the convenience of the description below, these algorithms are called the three band model $(T B M)$, double three band baseline $(D T B B)$, four band model $(F B M)$, and four band baseline model $(F B B M)$, respectively.

\section{$T B M$}

These three algorithms are proposed to estimate PC using three spectral bands denoted as $\lambda_{1}, \lambda_{2}$, $\lambda_{3}$, respectively. Selection of these three wavelengths or spectral bands is based on the following assumptions: 1) $\lambda_{1}$ is sensitive to PC absorption; 2) $\lambda_{2}$ is less sensitive to PC absorption, but the absorption coefficients of NAP and CDOM at $\lambda_{2}$ should be similar to those at $\lambda_{1} ; 3$ ) the backscattering coefficients of OACs are spectrally neutral across $\lambda_{1}, \lambda_{2}$, and $\lambda_{3}$. The first TBM was constructed using $\lambda_{1}=630, \lambda_{2}=660$, and $\lambda_{3}=725 \mathrm{~nm}$ to estimate $\mathrm{PC}$, and obtained an $\mathrm{R}^{2}$ of 0.95, and a RMSE of $6.35 \mu \mathrm{g} / \mathrm{L}$ when applied to cultured CYB spectra measured with an ASD FieldSpec ${ }^{\circledR}$ HandHeld Spectroradiometer (Analytical Spectral Devices Inc., Boulder, CO, USA) [25]. Later the TBM for airborne hyperspectral sensors was established with $\lambda_{1}=615, \lambda_{2}=600$, and $\lambda_{3}=725 \mathrm{~nm}$ for hyperspectral sensors Compact Airborne Spectrographic Imager-2 (CASI-2) (ITRES Research Ltd., Calgary, AB, Canada) and Airborne Imaging Spectrometer for Applications Eagle (AISA Eagle) (SPECIM, Oulu, NO, Finland), and performed well with $\mathrm{R}^{2}=$ 0.92, and $\mathrm{RMSE}=2.65 \mu \mathrm{g} / \mathrm{L}$ [35]. Duan et al. [36] established a TMB with three MERIS bands at $\lambda_{1}=620, \lambda_{2}=709$, and $\lambda_{3}=754 \mathrm{~nm}$ for estimating PC concentrations in three inland lakes in China (Lake Taihu, Lake Dongjiu and Lake Gehu). Nonetheless, the three band model is found to 
perform poorly for highly turbid waters or when CYB blooms do not dominate [26, 40-41], and other semi-analytical models are proposed using the assumptions for the three band model and additional spectral characteristics.

\section{$D T B B$}

The $D T B B$ algorithm is composed of double three band models and a midpoint baseline index. The first three band model (equation 3) uses bands are $\lambda_{1}=624, \lambda_{2}=600$, and $\lambda_{3}=725 \mathrm{~nm}$, while the second three band model (equation 4) uses $\lambda_{1}=624, \lambda_{2}=648$, and $\lambda_{3}=725 \mathrm{~nm}$.

$$
\begin{aligned}
& R 31=\frac{b_{b}(725)}{a_{w}(725)+a_{c d m}(725)+a_{\text {pigs }}(725)+b_{b}(725)} \times\left[\frac{a_{w}(624)+a_{c d m}(624)+a_{\text {pigs }}(624)+b_{b}(624)}{b_{b}(624)}\right. \\
& \left.-\frac{a_{w}(600)+a_{c d m}(600)+a_{\text {pigs }}(600)+b_{b}(600)}{b_{b}(600)}\right] \\
& R 32=\frac{b_{b}(725)}{a_{w}(725)+a_{c d m}(725)+a_{\text {pigs }}(725)+b_{b}(725)} \times\left[\frac{a_{w}(624)+a_{c d m}(624)+a_{\text {pigs }}(624)+b_{b}(624)}{b_{b}(624)}\right. \\
& \left.-\frac{a_{w}(648)+a_{c d m}(648)+a_{\text {pigs }}(648)+b_{b}(648)}{b_{b}(648)}\right]
\end{aligned}
$$

The selection of these spectral bands for the construction of the two three band indices was inspired by the TBM in [35] with $\lambda_{1}=624 \mathrm{~nm}$ being sensitive to PC, but $\lambda_{2}=600 \mathrm{~nm}$ or $648 \mathrm{~nm}$ being less sensitive to PC and able to compensate for the NAP and CDOM absorption (i.e. $a_{c d m}$, hereafter $c d m$ represents both NAP and CDOM) at $\lambda_{1}$. A neutral backscattering is assumed for wavelengths $\lambda_{1}$ and $\lambda_{2}$. Additionally, the assumption of dominant water absorption $\lambda_{3}=725 \mathrm{~nm}$ implies $a_{c d m}(725)=a_{\text {pigs }}(725) \approx 0[11,42]$, and rearrangement of equation 3 and 4 results in equations 5 and 6 [37]:

$a_{p i g s}(624)-a_{p i g s}(600)=\left[a_{w}(725)+b_{b}(725)\right] R 31-a_{w}(624)+a_{w}(600)-a_{c d m}(624)+a_{c d m}(600)$ 


$$
a_{\text {pigs }}(624)-a_{p i g s}(648)=\left[a_{w}(725)+b_{b}(725)\right] R 32-a_{w}(624)+a_{w}(648)-a_{c d m}(624)+a_{c d m}(648)
$$

Based on the $M R B I$ by Dekker [3], a midpoint absorption baseline was proposed to form the $D T B B$ model by use of the phytoplankton absorption at 600, 624, and $648 \mathrm{~nm}$ [37]:

$$
a_{p c}(624)=a_{p i g}(624)-0.5\left(a_{p i g}(600)+a_{p i g}(648)\right)
$$

The advantage of $D T B B$ is capable of removing the $c d m$ interference with PC absorption at 624 nm using $0.5 \times\left[a_{c d m}(600)+a_{c d m}(648)\right]-a_{c d m}(624) \approx 0$, and the interference of Chl-a by subtraction of $0.5 \times\left[a_{\text {pigs }}(600)+a_{p i g s}(648)\right]$ from $a_{\text {pigs }}(624)$. Application of equations 5 and 6 to equation 7 results in an expression for $a_{p c}(624)$.

Compared with the $T B M$, the advantage of $D T B B$ is able to compensate for the interference of Chla with PC absorption at $624 \mathrm{~nm}$. However, the backscattering at $\lambda_{3}$ is accounted for by use of an equation by Simis et al. [11] and Gons et al. [43]. Application of DTBB for estimating PC concentrations in Eagle Creek and Geist Reservoirs (USA) resulted in an $\mathrm{R}^{2}$ of 0.85 and a relative RMSE (rRMSE) of $31.4 \%$. As expected, DTBB is less sensitive to the absorption interference of NAP, CDOM, Chl-a, and performed better than classical three band algorithms at low PC concentrations ( $\mathrm{PC} \leq 50 \mathrm{ug} / \mathrm{L})$. However, one caveat is that the $a_{p c}(624)$ expressed by equation 7 is relative to the baseline between 600 and $648 \mathrm{~nm}$ where PC has non-zero absorption values, implying that the derived $a_{p c}(624)$ should be have a relatively smaller value than the actual $a_{p c}(624)$. This may explain why the $a_{p c}^{*}(620)$ values used in Dekker et al. [3] and Li et al. [37] are lower than the values used in Simis et al. [11, 42] as described later. 
The first four band model for PC estimation was proposed by Le et al. [38]. Selection of the first two bands is based on the same assumption as those for the three band algorithm, but bands 3 and 4 are selected in the near infrared region so that non-water absorption is eliminated. Assuming the neutral backscattering across four bands, the four band model $(F B M)$ is expressed as:

$F B M=\left[R_{r s}\left(\lambda_{1}\right)^{-1}-R_{r s}\left(\lambda_{2}\right)^{-1}\right] /\left[R_{r s}\left(\lambda_{4}\right)^{-1}-R_{r s}\left(\lambda_{3}\right)^{-1}\right]=a_{p c} /\left[a_{w}\left(\lambda_{4}\right)-a_{w}\left(\lambda_{3}\right)\right]$

A set of four bands $\lambda_{1}=630, \lambda_{2}=645, \lambda_{3}=695$, and $\lambda_{4}=730 \mathrm{~nm}$ was used by the $F B M$ resulting in a RMSE of $4.83 \mathrm{mg} \mathrm{m}^{-3}$ and $6.8 \mathrm{mg} \mathrm{m}^{-3}$ when applied to spectral datasets collected for Lake Taihu in 2007 and 2008, respectively.

\section{FBBM}

The FBBM is the second four band algorithm proposed for estimating PC [39]. This four band baseline algorithm has the assumptions similar to those for the $D T B B$, but there are two differences. One is that the $F B B M$ uses the interpolation of non-PC component absorption at bands $\lambda_{2}\left(<\lambda_{1}\right)$ and $\lambda_{3}\left(>\lambda_{1}\right)$ with a weight value $\eta_{\lambda_{3}}^{\lambda_{2}}\left(\lambda_{1}\right)$ ranging from -0.1 to 1.1 to approximate non-PC component absorption at wavelength $\lambda_{1}$, and this linear interpolation absorption baseline differs from the $D T B B$ which uses a weight value of 0.5 ; the other difference is that the $F B B M$ assumes a neutral backscattering across bands $\lambda_{1}, \lambda_{2}, \lambda_{3}$, and $\lambda_{4}$, whereas the DTBB uses $b_{b}\left(\lambda_{1}\right) \approx b_{b}\left(\lambda_{2}\right)$, and an explicit expression for $b_{b}\left(\lambda_{3}\right)$. The $F B B M$ is expressed as:

$$
\begin{gathered}
F B B M=\left[R_{r s}\left(\lambda_{1}\right)^{-1}-\eta_{\lambda_{3}}^{\lambda_{2}}\left(\lambda_{1}\right) R_{r s}\left(\lambda_{2}\right)^{-1}-\left(1-\eta_{\lambda_{3}}^{\lambda_{2}}\left(\lambda_{1}\right)\right) R_{r s}\left(\lambda_{3}\right)^{-1}\right] R_{r s}\left(\lambda_{4}\right) \\
\propto\left[a_{p c}\left(\lambda_{1}\right)+a_{w}\left(\lambda_{1}\right)-a_{w}\left(\lambda_{2}\right)-a_{w}\left(\lambda_{3}\right)\right] / a_{w}\left(\lambda_{4}\right)
\end{gathered}
$$


This expression indicates an inherent correlation of this four band index to PC concentration, and has been evaluated with the spectral bands of MERIS. As shown in Figure 2, the FBBM resulted in an $\mathrm{R}^{2}$ of 0.73 and a RMSE of $27.69 \mu \mathrm{g} / \mathrm{L}$ when tested with datasets collected from aquatic systems located in the USA, the Netherlands, and in China [39].

Insert Figure 2 here

\section{Semi-Analytical Algorithms for PC Estimation}

Table 5 shows three semi-analytical PC algorithms to date. Simis et al. [11] proposed the earliest semi-analytical PC algorithm using nested band ratios $(N B R)$ and three empirical relationships. The second algorithm was developed by Mishra et al. [44-45] using the classical quasi-analytical algorithm (QAA) and an empirical procedure for removal of overlapping Chl-a absorption at 620 $\mathrm{nm}$. The third algorithm, an extension of IOP Inverse Model for Inland Waters (IIMIW) was developed by $\mathrm{Li}$ et al. [46] to partition non-water absorption coefficient $\left(\mathrm{a}_{\mathrm{t}-\mathrm{w}}(\lambda)\right)$ into the contribution of NAP, CDOM, non-PC pigments, and PC. These three algorithms, hereafter called $N B R, Q A A_{p c}$ and EIIMIW, respectively, are used to derive the PC absorption at $620 \mathrm{~nm}$, and then divide with the specific absorption coefficient of PC to calculate its concentration. The use of some empirical relations makes it appropriate to consider these algorithms being semi-analytical.

$N B R$

$N B R$ uses the first two assumptions on PC absorption at wavelengths $\lambda_{1}$ and $\lambda_{2}$ that are used to develop other semi-empirical algorithms, and assumes a neutral backscattering between these wavelengths. The total absorption coefficients at $665 \mathrm{~nm}$ and $620 \mathrm{~nm}$ are derived by applying the 
relationship between the IOP and remote sensing reflectance to band ratios $\mathrm{R}_{\mathrm{rs}}(709) / \mathrm{R}_{\mathrm{rs}}(665)\left(\lambda_{1}=\right.$ $665 \mathrm{~nm}$ and $\left.\lambda_{2}=709 \mathrm{~nm}\right)$, and $R_{\mathrm{rs}}(709) / \mathrm{R}_{\mathrm{rs}}(620) \quad\left(\lambda_{1}=620 \mathrm{~nm}\right.$ and $\left.\lambda_{2}=709 \mathrm{~nm}\right)$, respectively, in which water absorption and backscattering across these wavelengths are considered. Two empirical constant $\gamma$ and $\delta$ are applied to the total absorption coefficients derived for $665 \mathrm{~nm}$ and $620 \mathrm{~nm}$, respectively to correct for the effect of CDOM and NAP, resulting in the absorption coefficient of Chl-a at $665 \mathrm{~nm}$, and phytoplankton at $620 \mathrm{~nm}$. Finally, the absorption of Chl-a at $665 \mathrm{~nm}$ derived from $\mathrm{R}_{\mathrm{rs}}(709) / \mathrm{R}_{\mathrm{rs}}(665)$ is converted to its absorption at $620 \mathrm{~nm}$ with a correlation coefficient between at the two wavelengths of in vivo Chl-a absorption $(\varepsilon)$, and then nested into the absorption of phytoplankton at $620 \mathrm{~nm}$ derived from $\mathrm{R}_{\mathrm{rs}}(709) / \mathrm{R}_{\mathrm{rs}}(620)$, resulting in the absorption coefficient of PC at $620 \mathrm{~nm}$ as shown in Table 5. where $\gamma$ is a factor for correcting for CDOM and NAP absorption $\lambda_{1}=665 \mathrm{~nm}$ and pigment absorption at $\lambda_{2}=709 \mathrm{~nm}$.

The most obvious advantage of $N B R$ is to compensate for the interference of Chl-a with PC absorption at $620 \mathrm{~nm}$, but the correction for the absorption of CDOM and NAP is empirical and required for different water bodies [47-48]. Le et al. [38] showed that the nested band ratio algorithm did not perform as well as the four band algorithm, but Duan et al. [36] recommended to use the nested band ratio algorithm instead of the three band algorithm.

$Q A A_{p c}$

$Q A A_{p c}$ first utilizes the QAA to derive the $a_{p h y}(\lambda)$ at 665 and $620 \mathrm{~nm}$, respectively, each of which is considered to the summation attributed to the absorption of PC and Chl-a as shown by the two relationships in Table 5. Solving these two relations for the PC absorption at $620 \mathrm{~nm}\left(a_{p c}(620)\right)$ becomes straightforward when $\psi_{1}$ and $\psi_{2}$ are defined to be $a_{\text {chl-a }}(665) / a_{\text {chl-a }}(620)$ and $a_{\mathrm{pc}}(665) /$ 
$a_{\mathrm{pc}}(620)$, respectively. $Q A A_{p c}$ ' performance depends on optimizing $\psi_{1}$ and $\psi_{2}$ factors. When applied to MERIS spectra of hypereutrophic catfish ponds, $Q A A_{p c}$ gave rise to a strong PC estimation with an $\mathrm{R}^{2}$ of 0.99 and a relative error of $30.7 \%$.

\section{EIIMIW}

The EIIMIW aims at partitioning non-water absorption coefficient $\left(\mathrm{a}_{\mathrm{t}-\mathrm{w}}(\lambda)\right)$ into the contribution of NAP, CDOM, non-PC pigments, and PC [46, 49]. The first assumption is the dominance of water absorption at $709 \mathrm{~nm}$ over $\mathrm{cdm}$ and phytoplankton, i.e. $a(709) \approx a_{w}(709)$, which is used to derive the total non-water constituent absorption at a wavelength from the ratio of $R_{r s}(709)$ to $R_{r s}(\lambda)$ and using $b_{b}(709)$ which is derived from particle backscattering at $560 \mathrm{~nm}\left(b_{b p}(560)\right)$ and $b_{b}(778)$. The second assumption is $a_{c d m}(\lambda)=a_{p c}(\lambda)=0$ for $\lambda=665 \mathrm{~nm}$ or larger, implying $a_{p h-p c}(665) \approx a_{t-w}(665)$ and $a_{p h-p c}(675) \approx a_{t-w}(675)$. Li et al. [37] observed a strong correlation between $a_{t-w}(665)$ and $a_{t-}$ ${ }_{w}(675)$, implying a relationship $a_{p h-p c}(\lambda)=\mathrm{Cl}(\lambda) a_{p h-p c}(675)+\mathrm{C} 2(\lambda)$ where $\mathrm{C}_{1}(\lambda)$ and $\mathrm{C}_{2}(\lambda)$ are spectral constants derived from $a_{\text {phy-pc }}(\lambda)$ measured in pigment extraction using acetone in laboratory and shown in the Appendix B of Li al. [46]. Therefore, the absorption of NAP, CDOM, and PC at a wavelength $\lambda\left(a_{c d m+p c}(\lambda)\right)$ can be calculated as the difference between $a_{t-w}(\lambda)$ and $a_{p h-}$ ${ }_{p c}(\lambda)$. The third assumption is $a_{p c}(\lambda)=0$ for $\lambda=510 \mathrm{~nm}$ or 412 , i.e. $a_{c d m}(412)=a_{t-w}(412)-a_{p h y-}$ $p c(412)$ and $a_{c d m}(510)=a_{t-w}(510)-a_{p h y-p c}(510)$, then the $c d m$ absorption at a wavelength $\lambda\left(a_{c d m}(\lambda)\right)$ can be derived from $a_{c d m}(412)$ and $a_{c d m}(510)$. At last, $a_{p c}(620)$ is calculated to be $a_{p c}(620)=a_{t-}$ ${ }_{w}(620)-a_{p h y-p c}(620)-a_{c d m}(620)$.

The EIIMIW was applied to water samples collected from reservoirs of Northeast China, Lake Tai of southern China, rivers and lakes of South Australia in addition to the three Central Indiana 
reservoirs for deriving the IOPs of phytoplankton, PC and CDM. When calibrated with data collected in 2010 from three Indiana reservoirs, the EIIMIW estimated the absorption spectra of both CDM $\left(\mathrm{a}_{\mathrm{cdm}}(\lambda)\right)$ and phytoplankton $\left(\mathrm{a}_{\mathrm{ph}}(\lambda)\right)$ with $\mathrm{R}^{2} \geqslant 0.80$ and a relative root mean square error $(\mathrm{rRMSE}) \leqslant 31.79 \%$ for $\mathrm{a}_{\mathrm{cdm}}(412), \mathrm{a}_{\mathrm{ph}}(443), \mathrm{a}_{\mathrm{ph}}(620)$, and $\mathrm{a}_{\mathrm{ph}}(665)$. The EIIMIW achieved more accurate $\mathrm{PC}$ estimation with $\mathrm{R}^{2}=0.81, \mathrm{rRMSE}=33.60 \%$, and mean relative error $(\mathrm{RE})=$ $49.11 \%$ than the widely used semi-empirical algorithm with $\mathrm{R}^{2}=0.73, \mathrm{rRMSE}=45.09 \%$, and mean $\mathrm{RE}=182.29 \%$ for the same dataset. Figure 3 shows the EIIMIW validation on data collected from 2005 to 2008 from three Indiana reservoirs, USA, and a strong performance of EIIMIW is evident compared to the $N B R$ model, particularly for low PC range samples ([PC] $\leq 50 \mu \mathrm{g} / \mathrm{L}$ ).

Insert Figure 3 here

\section{Performance Comparison among Semi-Empirical and Semi-Analytical Models}

Recently, several studies have been devoted to comparison of various semi-empirical and semianalytical models for the estimation of PC concentration [40, 50-51]. The discussion below will be focused on describing the research by Li and Song [16], Liu et al. [39], Pyo et al. [52], and Riddick et al. [53], in which the comparison of PC algorithms was carried out either based on a large dataset [39] or for a relatively complete list of currently available semi-empirical and semianalytical algorithms [52-53]. Table 4 shows the comparison results from these studies.

\section{Datasets for three reservoirs of central Indiana, USA}

Li and Song [16] systematically compared the performance of various empirical, semi-empirical, and semi-analytical PC algorithms with in situ measured reflectance spectra for three central 
Indiana reservoirs: Eagle Creek, Geist and Morse. For these three reservoirs, an ASD FieldSpec ultraviolet/visible and near-infrared (UV/VNIR) spectroradiometer (Analytical Spectral Devices, Inc., Boulder, CO, USA) was used to measure the remote sensing reflectance above the water surface $\mathrm{R}_{\mathrm{rs}}(\lambda)$ in 2005 and 2006, and an Ocean Optics USB4000 unit (Ocean Optics, Inc., Dunedin, FL, USA) with dual radiometers to measure remote sensing reflectance below the water surface $\mathrm{r}_{\mathrm{rs}}(\lambda)$ in 2007, 2008, and 2010, and resulted in a total of 649 water samples for which both in situ spectra and PC concentrations were available. $B R_{650 / 620}, M R B I, N B R$, and EIIMIW were compared for their performance, and $\mathrm{R}^{2}=0.54,0.21,0.73$, and 0.74 , were obtained respectively.

\section{Datasets for reservoirs in the USA, the Netherlands, and China}

Liu et al. [39] compared the performance of various empirical, semi-empirical, and semi-analytical PC algorithms with in situ reflectance spectra measured with an Ocean Optics USA400 unit (Ocean Optics, Inc., Dunedin, FL, USA) radiometer in 2010 for Eagle Creek, Geist and Morse reservoirs located in central Indiana, USA, with a PR-650 (Photo Research) in the summers of 2004 and 2005 for Lake IJsselmeer (LIJ) in the Netherlands, and with a FieldSpec spectroradiometer (Analytical Spectral Devices, Inc., Boulder, CO, USA) in 2016 for Lake Taihu (LTH), Lake Chaohu (LCH) and Lake Hengshui (LHS) in China. Algorithms that were compared in this study were $B R_{650 / 620}, P C I, T B M$, and $F B B M$, and $\mathrm{R}^{2}=0.63,0.178,0.701$, and 0.73 were obtained, respectively.

\section{Datasets for Baekje reservoir in South Korea}

Pyo et al. [52] compared the performance of semi-analytical PC algorithms with in situ reflectance spectra measured from June to Oct., 2016 with a FieldSpec HandHeld 2 spectroradiometer (ASD 
Inc., Boulder, CO, USA) having a wavelength range of 325-1075 nm for Baekje reservoir located in the main stream of Geum River, South Korea. Algorithms that were optimized and then assessed against a total of 160 samples with PC concentration ranging from 0 to $1014 \mu \mathrm{g} / \mathrm{L}$ included $N B R$ and EIIMIW, for which $\mathrm{R}^{2}=0.53$ and 0.83 were obtained, respectively. Therefore, the EIIMIW was favorable over $N B R$ for estimating PC concentrations in this reservoir. Nonetheless, it is important to note that the original EIIMIW forced a zero $a_{c d m}$ at $709 \mathrm{~nm}$ before removing the $c d m$ absorption from the total non-water absorption [46]. Table S2 that was provided by Pyo et al. [52] does not indicate whether this step was taken into consideration, but this could explain why the EIIMIW resulted in so dramatically different $\mathrm{R}^{2}$ values with $\left(\mathrm{R}^{2}=0.83\right)$ and without being recalibrated $\left(\mathrm{R}^{2}=0\right)$.

\section{Datasets for Lake Balaton, Hungary}

Riddick et al. [53] performed a comprehensive comparison among various PC algorithms with a MERIS and in situ reflectance dataset of Lake Balaton, Hungary. The PC concentrations were measured by Balaton Limnological Institute (BLI) at 5 stations of this reservoir from 2010 to 2011 at a bi-weekly or monthly basis as well as at 30 stations from Aug.18 to 26, 2010, giving a PC range of $2.34-113.0 \mu \mathrm{g} / \mathrm{L}$. These PC datasets called the BLI and the Aug. 2010 datasets, respectively, were used to validate PC algorithms with the image spectra of a MERIS overpass within a time window of \pm 1 day.

Algorithms that were compared on 22 data pairs of PC concentration and MERIS spectrum at \pm 1 day windows were $B R_{650 / 620}, M R B I, P C I, T B M, N B R, Q A A_{p c}, E I I M I W$, and $F B B M$, which resulted in an $\mathrm{R}^{2}$ of $0.595,0.0992,0.091,0.662,0.71,0.00836,0.716$, and 0.634 , respectively, and a RMSE 
of $14.4,21.6,715,17.8,11.8,22.9,46.3$, and $16.5 \mu \mathrm{g} / \mathrm{L}$, respectively. These 22 samples were also separated based on the PC threshold $50 \mu \mathrm{g} / \mathrm{L}$. Schalles00, MRBI, PCI, TBM, NBR, QAApc, EIIMIW, and $F B B M$ were only validated on 19 samples having PC concentration less than $50 \mu \mathrm{g} / \mathrm{L}$, and resulted in an $\mathrm{R}^{2}$ of $0.554,0.0719,0.0588,0.77,0.793,0.44,0.697$, and 0.814 , respectively, and a RMSE of $13.57,17.84,766,10.4,10.7,9.76,20.2$, and $15.3 \mu \mathrm{g} / \mathrm{L}$, respectively. Based on the $\mathrm{R}^{2}$ and RMSE values for the PC algorithms subject to the comparison performed by this study, $N B R$ was determined to be the optimal PC algorithm instead of EIIMIW and FBBM because NBR resulted in lower RMSE values than EIIMIW and FBBM. However, additional investigations are still needed to compare $N B R, E I I M I W$ and $F B B M$ with each other because of the limitation to the work performed by Riddick et al. [53]. First, a small set of water samples from one lake was used in the comparison by Riddick et al. [53], whereas the $F B B M$ was optimized using a large number of water samples from inland waters in the Netherlands, central Indiana, and typical lakes in China and should be more transferable geographically. Second, the EIIMIW implemented by Riddick et al. [53] used a constant $S_{C D O M}=0.02 \mathrm{~nm}^{-1}$ to characterize $c d m$ absorption, whereas the original EIIMIW used the natural $\log$ transformed ratio of NAP absorption at $412 \mathrm{~nm}$ to that at $510 \mathrm{~nm}$ for describing $c d m$ absorption. Giving the high concentration of inorganic particle in Lake Balaton, it is not unexpected that the EIIMIW implemented by Riddick et al. (2019) resulted in a relatively large RMSE for Lake Balaton.

\section{Algorithms recommended for further examination}

Based on the results described above for the performance of various PC algorithms, it is evident that the semi-analytical algorithms $N B R$ and $E I I M I W$, and the semi-empirical $F B B M$ performed stronger than empirical algorithms $M R B I$ and $P C I$ showing the weakest performance along with 
another semi-analytical algorithm $Q A A_{p c}$. Empirical algorithms $B R_{650 / 620}$ and $T B M$ showed stronger performance than $M R B I, P C I$, and $Q A A_{p c}$, which can be explained by a high dataset dependent correlation between the former ratios and PC concentrations. Therefore, future investigation should focus on assessing, comparing and further improving the performance of $N B R$, EIIMIW, and FBBM and developing completely new algorithms in order to determine optimal algorithms for monitoring CYB blooms in regional and global scales.

\section{Practical Considerations and Current challenges}

Satellite- and airborne - based cyanobacteria monitoring

Detection or monitoring of inland water CYB blooms relies on the PC absorption feature around $620 \mathrm{~nm}$, but very few satellite sensors own this spectral channel. Satellite sensors such as those on Hyperion, HICO and MERIS used to have bands around $620 \mathrm{~nm}$, these sensors ended their data acquisition service in 2017, 2014 and 2012. Launched in April 28, 2018, the Ocean and Land Color Instrument (OLCI) on board Sentinel-3 has similar spectral configuration to the MERIS and is able to maintain data continuity of ENVISAT [54]. Italian PRecursore IperSpettrale della Missione Applicativa (PRISMA) was developed by the Italian Space Agency (ASI in Italian) and launched in Mar. 22, 2019. This sensor is able to acquire hyperspectral images at $30 \mathrm{~m}$ spatial resolution and 250 bands from 400 to $2500 \mathrm{~nm}$ [55]. Both the OLCI and PRISMA capable of acquiring images at $620 \mathrm{~nm}$ provide opportunities to assess the algorithms $N B R, E I I M I W$, and FBBM, and determine the best for monitoring CYB blooms of inland waters around the world. In addition, another two satellite hyperspectral sensors such as German Environmental Mapping and Analysis Program (EnMAP) and NASA's Hyperspectral Infra-Red Imager (HyspIRI) have been scheduled to launch in 2020 and 2022, respectively [56-57]. Hyperspectral sensors PRISMA EnMAP and 
HysPIRI will provide opportunities to determine the best PC algorithm among NBR, EIIMIW, and $F B B M$. Furthermore, PRISMA EnMAP and HysPIRI data would allow for assessing the DTBB, which cannot be done with the OLCI data in spite of its better performance than NBR and EIIMIW.

\section{Variability of PC specific absorption coefficient}

The convention of practicing semi-analytical algorithms for estimating PC is to divide the bulk PC absorption coefficient at $620 \mathrm{~nm}$ by the corresponding specific absorption coefficient, and different $a_{p c}^{*}(624)$ values result in different PC concentrations. For example, Dekker [3] reported that $a_{p c}^{*}(624)=0.0032 \pm 0.0012 \mathrm{~m}^{2}(\mathrm{mg} \mathrm{PC})^{-1}$ for the Netherlands inland waters, Li et al. [37] determined an average $a_{p c}^{*}(624)$ to be $0.0024 \mathrm{~m}^{2}(\mathrm{mg} \mathrm{PC})^{-1}$ for three central Indiana reservoirs, and these low values for $a_{p c}^{*}(620)$ have been attributed to the use of the baseline between 600 and $648 \mathrm{~nm}$ for determining $a_{p c}^{*}(620)$. However, high $a_{p c}^{*}(620)$ values of $0.0095 \mathrm{~m}^{2}(\mathrm{mg} \mathrm{PC})^{-1}$ and $0.007 \mathrm{~m}^{2}$ (mg PC) ${ }^{-1}$ were used by Simis et al. [11, 42], respectively, which have been attributed to the absorption of intracellular water-soluble compounds akin to sheath pigments found in cyanobacteria [37]. When assessing and comparing different PC algorithms, it is important to ensure that the performance assessment and comparison for different PC algorithms is performed with the same PC specific absorption coefficient.

\section{Variability of specific absorption coefficients of Non-PC constituents}

Semi-empirical and semi-analytical models are commonly built upon the assumption that the water constituent IOPs are spatially and seasonally stable or that the spectral shapes of individual constituent absorption and backscattering are known. These assumptions are often violated in real 
world applications. For example, the specific phytoplankton absorption coefficient $\left(a_{p h}^{*}\right)$ is defined to be the ratio of the phytoplankton absorption coefficient $\left(a_{p h}\right)$ to Chl-a concentration, and is known to vary across individual species grown in culture and among natural phytoplankton assemblages because of varying pigment composition and the package effect [58-60]. Some studies suggested $0.02 \mathrm{~m}^{2} / \mathrm{mg}$ for the average value of $a^{*}{ }_{p h}$ (using $675 \mathrm{~nm}$ as reference) [60-61], but this value could have a range of $0.01-0.033 \mathrm{~m}^{2} / \mathrm{mg}$ for New Zealand lakes [62], 0.005-0.05 $\mathrm{m}^{2} / \mathrm{mg}$ for Nebraska and Iowa lakes [63], and 0.01-0.025 $\mathrm{m}^{2} / \mathrm{mg}$ for three water reservoirs in northeastern Australia [64]. Investigators often use different power laws to describe $a_{p h}^{*}$ as a function of Chl-a concentration. Although this varying power law relationship may not have a significant influence on the performance of the $N B R$ and EIIMIW algorithms because the removal of Chl-a interference on PC estimation is performed using the correlation between Chl-a absorption coefficients at bands 665 and $620 \mathrm{~nm}$, this varying power law relationship should affect the performance of $F B B M$ in which the linear interpolation weight needs to be optimized. It is worth pointing out that $Q A A_{p c}$ did not perform as strong as $N B R, E I I M I W$, and $F B B M$, but the two summations of Chl-a and PC absorption coefficients at $665 \mathrm{~nm}$ and $620 \mathrm{~nm}$ in $Q A A_{p c}$ can be useful for improving the $F B B M$.

NAP and CDOM are another two substances interfering remote estimation for PC concentrations. The exponential function is often used to describe the spectral dependence of dissolved natter and detritus absorption [65-66], but the exponent varies as a result of seasonal and/or spatial changes in the origin and type of dissolved materials (humic vs. fulvic) [67] and non-alga particles (mineral sediments, non-algal organic detritus such as fecal matter, degrading phytoplankton cells, and living non-algal particulates) [68-69]. The exponent of CDOM $S_{\mathrm{CDOM}}$ can range from 0.01 to 0.02 
$\mathrm{nm}^{-1}[70-71]$ or even a wider range [72]. However, a true synthesis of the variability in $S_{\mathrm{CDOM}}$ for inland waters is difficult to obtain from existing in-situ data because the investigations were conducted over limited seasons and regional regions. The exponential slope for NAPs $S_{\mathrm{NAP}}$ has been reported to be $0.011 \mathrm{~nm}^{-1}$ for productive and CDOM- rich marine waters [73], $0.0123 \mathrm{~nm}^{-1}$ (a range of $0.0089-0.0178 \mathrm{~nm}^{-1}$ ) for European coastal waters [70], $0.011 \mathrm{~nm}^{-1}$ (a range of 0.0077$0.017 \mathrm{~nm}^{-1}$ ) for Lake Erie [69]. This variability in $S_{\mathrm{NAP}}$ may result from a wide range of particle types and a relative extreme proportion of mineral or organic matter observed by these studies [69]. The variability described for $S_{C D O M}$ and $S_{N A P}$ should affect the performance of $N B R$ in which two empirical constants are used to correct for the effect of CDOM and NAP on estimating the PC and Chl-a absorption at $620 \mathrm{~nm}$ and $665 \mathrm{~nm}$, respectively, implying the necessity for recalibrating $N B R$.

\section{Variability of Suspended matter backscattering coefficients}

The main scattering contributors in inland waters are organic suspended matter (OSM) and inorganic suspended matter (ISM). Morel [74] showed that the variation of non-absorbing particle scattering coefficient follows a power law decay, which is often a valid relationship for coastal and inland waters [75-79]. This power law relationship has two implications for assessing the semianalytical PC algorithms $N B R$ and $F B B M$ and the semi-empirical algorithm $D T B B$ because they all assume a neutral backscattering. First, a neutral backscattering could be invalid when the power relationship shows a rapid decay and the interband space for these three algorithms is very wide such as $620 \mathrm{~nm}$ vs. $709 \mathrm{~nm}$ in $N B R, 530 \mathrm{~nm}$ vs. $750 \mathrm{~nm}$ in $F B B M$, and $600 \mathrm{~nm}$ vs. $725 \mathrm{~nm}$ in $D T B B$. Second, spectral scattering coefficients have been shown a significant departure from a power law decay at strong spectral absorption bands [80-82], and the power law model has been modified to account for the effect of particulate absorption [78]. These observations imply that a further 
correction for the effect of $b_{b}(\lambda)$ on the performance of $N B R, F B B M$, and $D T B B$ is necessary for achieving a reliable $\mathrm{PC}$ retrieval for very turbid water bodies.

\section{Conclusions}

Toxic cyanobacterial blooms are of great concern due to embedded implications for alternated biodiversity, public health, and for overall ecosystem health of inland waters. The development of remote sensing approaches to efficiently monitoring cyanobacterial blooms has important implications for effectively managing cyanobacterial blooms, and this critically relies on highly performing PC estimation algorithms.

Remote sensing algorithms for PC estimation are grouped into empirical, semi-empirical and semianalytical methods. In this chapter, thirteen of these methods have been described with twelve of them being reviewed and compared with each other based on their performances on in situ measured field reflectance spectra, and airborne or satellite sensor collected image spectra. Five empirical PC algorithms show data dependent performances with the MRBI and PCI being consistently weaker than the three band ratio models, which can be attributed to a strong interference of non-PC constituents with a relatively weaker PC absorption at $620 \mathrm{~nm}$. Nonetheless, when these band ratios are improved with the baseline idea embedded in the MRBI and $P C I$, semi-empirical models especially $D T B B$ and $F B B M$ can be established and show stronger performance than the $T B M$ with $D T B B$ even performing stronger than the $N B R$, a semi-analytical model. Assessing three semi-analytical models indicates that the NBR and EIIMIW consistently performed well compared to the $Q A A_{p c}$. However, given a large variability of non-PC constituents in their inherent optical properties, one caveat for applying the EIIMIW is to carefully follow the 
original model step for calculating the parameter $a_{\mathrm{cdm}}$, while for applying the $N B R$ it is necessary to recalibrate two empirical parameters for removing the interference of NAP and CDOM.

Despite being shown to perform stronger than the $N B R$ for estimating PC, so far neither $D T B B$ nor $F B M$ has been examined extensively with satellite MERIS and OLCI images because neither sensor has a spectral channel at $645 \mathrm{~nm}$ required for implementing semi-empirical $D T B B$ and $F B M$. With the availability of hyperspectral satellite images from PRISMA, EnMAP, and HyspIRI, both $D T B B$ and $F B M$ should be evaluated together with $E I I M I W$ and $N B R$ for a possibly improved cyanobacterial detection and management at large or regional scales.

\section{References}

1. Millie, D.F.; Baker, M.C.; Tucker, C.S.; Vinyard, B.T.; Dionigi, C.P. High-resolution airborne remote sensing of bloom-forming phytoplankton. Journal of Phycology 1992, 28, 281-290.

2. Mittenzwey, K.H.; Gitelson, A.A.; Kondratiev, K.Y. Determination of chlorophyll a of inland waters on the basis of specral reflectance. Limnology and Oceanography 1992, 37, 147-149.

3. Dekker, A.G. Detection of Optical Water Quality Parameters for Eutrophic Waters by High Resolution Remote Sensing. Ph. D. Dissertation, Vrije University Amsterdam, 1993.

4. Gitelson, A.A.; Laorawat, S.; Keydan, G.P.; Vonshank, A. Optical properties of dense algal culture outdoors and their application to remote estimation of biomass and pigment concentration in Spirulina Platensis (Cyanobacteria). Journal of Phycology 1995, 31,828834. 
5. Yacobi, Y.Z.; Gitelson, A.; Mayo, M. Remote sensing of chlorophyll in Lke Kinneret using high-spectral-resolution rediometer and Landsat TM, spectral features of reflectance and algorithm development. Journal of Plankton Research 1995, 17, 2155-2173.

6. Kuster, T.; Hannonen, T.; Kallio K.; Koponen, S.; Pulliainen, J.; Pyhalahti, T. Monitoring of turbid coastal and inland water by airborne imaging spectometer AISA. Geoscience and Remote Sensing Symposium Proceedings 1998, 5, 2597-2599.

7. Fraser, R.N. Hyperspectral remote sensing of turbidity and chlorophyll a among Nebraska Sand Hills lakes. International Journal of Remote Sensing 1998, 19, 1579-1589.

8. Schalles, J.F.; Yacobi, Y.Z. Remote detection and seasonal patterns of phycocyanin, carotenoid and chlorophyll pigments in eutrophic waters. Arch. Hydrobiol. Spec. Issues Advanc. Limnol. 2000, 55, 153 - 168.

9. Kallio, K.; Kuster, T.; Hannonen, T.; Koponen, S.; J. Pullianinen, J.; Vepsalainen, J. Retrieval of water quality from airborne imaging spectromentry of various lake types in differen season. Science of the Total Environment 2001, 268,59-77.

10. Vincent, R.K.; Qin, X.; McKay, R.M.L.; Miner, J.; Czajkowski, K.; Savino, J.; Bridgeman, T. Phcyocyanin detection from Landsat TM data for mapping cyanobacterial blooms in Lake Erie. Remote Sensing of Environment 2004, 89,381-392.

11. Simis, S.G.; Peters, S.W.; Gons, H. Remote Sensing of the cyanobacterial pigment phycocyanin in turbid inland water. Limnology and Oceanography 2005, 50, 237-245.

12. Zimba, P.V.; Gitelson, A. Remote estimation of chlorophyll concentration in hypereutrophic aquatic systems: Model tuning and accuracy optimization. Aquaculture 2006 $256,272-286$. 
13. Li, L.; Pascual, D.L.; Tedesco, L. P.; Randolph, K.L.; Sengpiel, R.E.; Hall, B.E. 2006. Developing a survey tool for the rapid assesment of blue-green algae in Central Indiana's reservoirs. Central Indiana Water Ressources Partnership/ Center for Earth and Environmental Science, IUPUI. Indianapolis, 2006.

14. Robertson, A.L. Using Band Ratio, Semi-empirical, Curve Fitting, and Partial Least Squares (PLS) Models to Estimate Cyanobacterial Pigment Concentration from Hyperspectral Reflectance. M. S. Thesis, Indiana University-Purdue University Indianapolis, 2009, pp. 108.

15. Matthews, M.W. A current review of empirical procedures of remote sensing in inland and near-coastal transitional waters. International Journal of Remote Sensing 2011, 32, 68556899.

16. Li, L.; Song, K. Bio-optical modeling of phycocyanin. in bio-optical modeling and remote sensing of inland waters; Elsevier: Amsterdam, The Netherlands, 2017; pp. 233-262, ISBN 978-0-12-804644-9.

17. Yan, Y.; Bao, Z.; Shao, J. Phycocyanin concentration retrieval in inland waters: A comparative review of the remote sensing techniques and algorithms. Journal of Great Lakes Research 2018, 44, 748-755.

18. Han, L.; Rundquist, D.C. Comparison of NIR/red ratio and first derivative of reflectance in estimating algal-chlorophyll concentration: A case study in a turbid reservoir, Remote Sensing of Environment 1997, 62,253-261.

19. Rundquist, D.C.; Han, L.; Schalles, J.F.; Peake, J.S. Remote measurement of algal chlorophyll in surface waters: the case for the first derivative of reflectance near $690 \mathrm{~nm}$. Photogrammetric Engineering and Remote Sensing 1996, 62,195-200. 
20. Dekker, A.G.; Malthus, T. J.; Seyhan, E. Quantitative modeling of inland water quality for high resolution MSS system, IEEE Transactions on Geoscience and Remote Sensing 1991, $29,89-95$.

21. Gitelson, A. The peak near $700 \mathrm{~nm}$ on radiance spectra of algae and water: Relationships of its magnitude and position with chlorophyll concentration, International Journal of Remote Sensing 1992, 13, 3367-3373.

22. Gordon, H.R.; Brown, O.B.; Jacobs, M.M. Computed relationships between the inherent and apparent optical properties of a flat homogeneous ocean. Applied Optics 1975, 14417 $-14427$.

23. Morel, A.; Gentili, B. Diffuse-reflectance of oceanic waters. 2. bidirectional aspects. Applied Optics 1993, 32, 6864-6879.

24. Morel A; Gentili B. Diffuse reflectance of oceanic waters .3. Implication of bidirectionality for the remote-sensing problem. Applied Optics 1996, 35, 4850-4862.

25. Hunter, P.D.; Tyler, A.N.; Willby, N.J.; Gilvear, D.J. The spatial dynamics of vertical migration by Microcystis aeruginosa in a eutrophic shallow lake: A case study using high spatial resolution time-series airborne remote sensing. Limnology and Oceanography $2008 ; 53,2391-2406$.

26. Li, L.; Sengpiel, R.E.; Pascual, D.L.; Tedesco, L.P.; Wilson, J.S.; Soyeux, E. Using hyperspectral remote sensing to estimate chlorophyll-a and phycocyanin in a mesotrophic reservoir. International Journal of Remote Sensing 2010, 31, 4147-4162.

27. Mishra, S.; Mishra, D.R.; Schluchter, W.M. A novel algorithm for predicting phycocyanin concentrations in cyanobacteria: a proximal hyperspectral remote sensing approach. Remote Sensing 2009; 1, 758-775. 
28. Ogashawara, I.; Mishra, D.; Mishra, S.; Curtarelli, M.; Stech, J. A performance review of reflectance based algorithms for predicting phycocyanin concentrations in inlandwaters. Remote Sensing 2013, 5, 4774-4798.

29. Song, K.; Li, L.; Li, Z.; Tedesco, L.; Hall, B.; Shi, K. Remote detection of cyanobacteria through phycocyanin for water supply source using three-band model. Ecological Informatics 2013, 15, 22_33.

30. Wynne, T.; Stumpf, R.; Tomlinson, M.; Warner, R.; Tester, P.; Dyble, J.; Fahnenstiel, G. Relating spectral shape to cyanobacterial blooms in the Laurentian Great Lakes. International Journal of Remote Sensing 2008, 29, 3665-3672.

31. Wynne, T.T.; Stumpf, R.P.; Briggs, T.O. Comparing MODIS and MERIS spectral shapes for cyanobacterial bloom detection. International Journal of Remote Sensing 2013, 34, $6668-6678$.

32. Wynne, T.T.; Stumpf, R.P. Spatial and Temporal Patterns in the Seasonal Distribution of Toxic Cyanobacteria in Western Lake Erie from 2002-2014, Toxins 2015, 7, 1649-1663; doi:10.3390/toxins7051649.

33. Qi, L.; Hu, C.; Duan, H.; Cannizzaro, J.; Ma, R. Anovel MERIS algorithm to derive cyanobacterial phycocyanin pigment concentrations in a eutrophic lake: Theoretical basis and practical considerations. Remote Sensing of Environment 2014, 154, 298-317.

34. Stumpf, R.P.; Davis, T.W.; Wynne, T.T.; Graham, J.L.; Loftin, K.A.; Johengen, T.H.; Gossiaux, D.; Palladino, D.; Burtner, A. Challenges for mapping cyanotoxin patterns from remote sensing of cyanobacteria. Harmful Algae 2016, 54, 160-173. 
35. Hunter, P.D.; Tyler, A.N.; Carvalho, L.; Codd, G.A.; Maberly, S.C. Hyperspectral remote sensing of cyanobacterial pigments as indicators for cell populations and toxins in eutrophic lakes. Remote Sensing of Environment 2010, 114, 2705-2718.

36. Duan, H.; Ma, R.; Hu, C. Evaluation of remote sensing algorithms for cyanobacterial pigment retrievals during spring bloom formation in several lakes of East China. Remote Sensing of Environment 2012, 126, 126-135.

37. Li, L.; Li, L.; Shi, K.; Li, Z.; Song, K. A semi-analytical algorithm for remote estimation of phycocyanin in inland waters. Science of the Total Environment 2012, 435-436, 141150.

38. Le, C.; Li, Y.; Zha, Y.;Wang, Q.; Zhang, H.; Yin, B. Remote sensing of phycocyanin pigment in highly turbid inland waters in Lake Taihu, China. International Journal of Remote Sensing 2011, 32, 8253-8269.

39. Liu, G.; Simis, S.G.H.; Li, L.;Wang, Q.; Li, Y.; Song, K.; Lyu, H.; Zheng, Z.; Shi, K. A four-band semi-analytical model for estimating phycocyanin in inlandwaters from simulated MERIS and OLCI Data. IEEE Transactions on Geoscience and Remote Sensing 2018, 56, 1374-1385.

40. Wozniak, M.; Bradtke, K.M.; Darecki, M.; Krezel, A. Empirical Model for Phycocyanin Concentration Estimation as an Indicator of Cyanobacterial Bloom in the Optically Complex CoastalWaters of the Baltic Sea. Remote Sensing 2016, 8, 212.

41. Ogashawara, I. The Use of Sentinel-3 Imagery to Monitor Cyanobacterial Blooms Environments 2019, 6, 60; doi:10.3390/environments6060060. 
42. Simis S.G.H.; Ruiz-Verdu, A.; Dominguez-Gomez, J.A; Pena-Martinez, R.; Peters, S.W.M.; Gons, H.J. Influence of phytoplankton pigment composition on remote sensing of cyanobacterial biomass. Remote Sensing of Environment 2007, 106, 414-427.

43. Gons, H. Optical teledetection of chlorophyll a in turbid inland waters. Environ. Sci. Technol. 1999, 33, 1127-1132.

44. Mishra, S.; Mishra, D.R.; Lee, Z.P.; Tucker, C.S. Quantifying cyanobacterial phycocyanin concentration in turbid productive waters: a quasi-analytical approch. Remote Sensing of Environment 2013, 133, 141-151.

45. Mishra, S.; Mishra, D.R.; Lee, Z.P. Bio-optical inversion in highly turbid and cyanobacteria-dominated waters. IEEE Transactions on Geoscience and Remote Sensing $2014,52,1,375-388$.

46. Li, L.H.; Li, L.; Song, K. Remote sensing of freshwater cyanobacteria: an extended IOP Inversion Model of Inland Waters (IIMIW) for partitioning absorption coefficient and estimating phycocyanin. Remote Sensing of Environment 2015 157, 9-23.

47. Randolph, K. L.; Wilson, J. S.; Tedesco, L. P.; Li, L.; Pascual, D. L.; Soyeux, E. Hyperspectral remote sensing of cyanobacteria in turbid productive water using optically active pigments, chlorophyll a and phycocyanin. Remote Sensing of Environment 2008, $112,4009-4019$.

48. Lyu, H.; Wang, Q.; Wu, C.; Zhu, L.; Yin, B.; Li, Y.M.; Huang, J.Z. Retrieval of phycocyanin concentration from remote-sensing reflectance using a semi-analytic model in eutrophic lakes. Ecological Informatics 2013, 18, 178-187. 
49. Li, L.H.; Li, L.; Song, K.; Li, Y.; Tedesco, L.P.; Shi, K.; Li, Z.C. An inversion model for deriving inherent optical properties of inland waters: establishment, validation and application. Remote Sensing of Environment 2013, 135, 150-166.

50. Ruiz-Verdu, A.; Simis, S.G.H.; de Hoyos, C.; Gons, H.J.; Pena-Martinez, R. An evaluation of algorithms for the remote sensing of cyanobacterial biomass. Remote Sensing of Environment 2008, 112, 3996-4008.

51. Ogashawara, I.; Mishra, D.R.; Mishra, S.; Curtarelli, M.P.; Stech, J.L. A performance review of reflectance based algorithms for predicting phycocyanin concentrations in inland waters. Remote Sensing 2013, 5 (10), 4774-4798.

52. Pyo, J.C.; Yachepsky,Y.; Baek, S.S.; Kwon, Y.S.; Kim, M.J.; Lee, H; Park, S.; Cha, Y.K.; Ha, R.; Nam, G.; Park, Y. G; Cho, K.H. Optimizing semi-analytical algorithms for estimating chlorophyll-a and phycocyanin concentrations in inland waters in Korea. Remote Sensing 2017, 9, 542; doi:10.3390/rs9060542.

53. Riddick, C.A.L.; Hunter, P.D.; Dominguez-Gómez, J.A.; Martinez-Vicente, V.; Présing, M.; Horváth, H.; Kovács, A.W.; Vörös, L.; Zsigmond, E.; Tyler, A, N. Optimal cyanobacterial pigment retrieval from ocean colour sensors in a highly turbid, optically complex lake. Remote Sensing 2019, 11, 1613; doi:10.3390/rs11131613.

54. Donlon, C.; Berruti, B.; Buongiorno, A.; Ferreira, M.H.; Femenias, P.; Frerick, J.; Goryl, P.; Klein, U.; Laur, H.; Mavrocordatos, C.; Nieke, J.; Redhan, H.; Seitz, B.; Stroede, J.; Sciarra, R. (2012). The global monitoring for environment and security (GMES) Sentinel3 mission. Remote Sensing of Environment 2012, 120, 37-57. doi: 10.1016/j.rse.2011.07.024 
55. Labate, D.; Ceccherini, M.; Cisbani, A.; De Cosmo, V.; Galeazzi, C.; Giunti, L.; Melozzim, M.; Pieraccini, S.; Stagi, M. The PRISMA payload optomechanical design, a high performance instrument for a new hyperspectral mission. Acta Astronautica 209, 65, 14291436. doi:10.1016/j.actaastro.2009.03.077

56. Stuffler, T.; Förster, K.; Hofer, S.; Leipold, M.; Sang, B.; Kaufmann, H.; Penné, B.; Mueller, A.; Chlebek, C. Hyperspectral imaging-An advanced instrument concept for the EnMAP mission (Environmental Mapping and Analysis Programme). Acta Astronautica 2009, 65(7-8), 1107-1112. doi:10.1016/j.actaastro.2009.03.042

57. National Research Council (NCR). Earth science and applications from space: national imperatives for the next decade. National Academy Press, Division on Engineering and Physical Sciences: Washington, DC, USA, 2017.

58. Bricaud, A.; Babin, M ; Morel, A. ; Claustre, H. Variability in the chlorophyll-specific absorption coefficients of naturnal phytoplankton: Analysis and parameterization. Journal of Geophysical Research 1995, 100, 13,321-13,332.

59. Bricaud, A; Stramski, D. Spectral absorption coefficients of living phytoplankton and noalgal biogenous matter: a comparison between the Peru upwelling area and the Sargasso Sea. Limnology and Oceanography 1990, 35, 562 - 582.

60. Le, C.F.; Li, Y.M.; Zha, Y.; Sun, D.Y.; Yin, B. Validation of a quasi-analytical algorithm for highly turbid eutrophic water of Meiliang Bay in Taihu Lake, China. IEEE Transactions on Geoscience and Remote Sensing 2009, 47(8),2492-2500.

61. Bricaud, A.; Morel, A; Prieur, L. Optical efficiency factors of some phytoplankters. Limnology and Oceanography 1983, 28, 816-832. 
62. Daviescolley, R. J; Vant, W. N. Absorption of Light by Yellow Substance in Fresh-Water Lakes. Limnology and Oceanography 1987, 32, 416-425.

63. Dall'olmo, G.; Gitelson, A. A. Effect of bio-optical parameter variability on the remote estimation of chlorophyll-a concentration in turbid productive waters: experimental results. Applied Optics 2005, 44, 3342-3342.

64. Campbell, G.; Phinn, S. R.; Daniel, P. The specific inherent optical properties of three subtropical and tropical water reservoirs in Queensland, Australia. Hydrobiologia 2011, 658, 233-252.

65. Bricaud, A.; Babin, M.; Claustre, H.; Ras, J.; Tieche, F. Light absorption properties and absorption budget of Southeast Pacific waters. Journal of Geophysical Research-Oceans 2010, 115, doi: 10.1029/2009JC005517

66. Bricaud, A.; Morel, A.; Babin, M.; Allali, K.; Claustre, H. Variations of light absorption by suspended particles with chlorophyll a concentration in oceanic (case 1) waters: Analysis and implications for bio-optical models. Journal of Geophysical Research 1998, $103,31,033-31,044$.

67. Song, K.S.; Zang, S.Y.; Zhao, Y.; Li, L.; Du, J.; Zhang, N.N.; Wang, X. D.; Shao, T. T.; Guan, Y.; Liu, L. Spatiotemporal characterization of dissolved carbon for inland waters in semi-humid/semiarid region, China, Hydrology and Earth System Sciences 2013, 10: 6559-6597, 2013b; doi:10.5194/hessd-10-6559-2013.

68. Stramski, D.; Babin, M.; Wozniak, S. Variation in the optical properties of terrigenous mineral-rich particulate matter suspended in sea water. Limnology and Oceanogragphy $2007,52,2,418-2433$. 
69. Binding, C. E.; Jerome, J.H.; Bukata, R.P.; Booty, W.G. 2008. Spectral absorption properties of dissolved and particulate matter in Lake Erie. Remote Sensing of Environment 2008, 112, 1702-1711.

70. Babin, M.; Morel, A.; Fournier-Sicre, V.; Fell, F.; Stramski, D. Light scattering properties of marine particles in coastal and open ocean waters as related to the particle mass concentration. Limnology and Oceanography 2003, 48, 843-859.

71. Kirk, J. T. O. Light and Photosynthesis in Aquatic Ecosystem. Cambridge University Press, Cambridge, Britain, 1994.

72. Kowalczuk, P. Seasonal variability of yellow substance absorption in the surface layer of the Baltic Sea. Journal of Geophysical Research-Oceans 1999, 104, 30047-30058.

73. Roesler, C. S.; Perry, M. J.; Carder, K. L. Modeling in situ phytoplankton absorption from total absorption spectra in productive inland marine waters. Limnology and Oceanography $1989,34,1,510-1,523$.

74. Morel, A. Optical Modeling of the upper ocean in relation to its biogenous matter content (Case-I Waters). Journal of Geophysical Research-Oceans 1988, 93, 10749-10768.

75. Morel, A.; Gentili, B.; Chami, M.; Ras, J. Bio-optical properties of high chlorophyll Case 1 waters and of yellow-substance-dominated Case 2 waters. Deep-Sea Research Part I 2006, 53, 1439-1459.

76. Roesler, C. S.; Boss, E. Spectral beam attenuation coefficient retrieved from ocean color inversion. Geophysical Research Letters 2003, 30,1468, 2003.

77. Song, Q. J.; Tang, J. W. The study on the scattering properties in the Huanghai Sea and East China Sea. Acta Oceanologica Sinica 2006, 28, 56-63. 
78. Doxaran, D.; Ruddick, K.; McKee, D.; Gentili, B.; Tailliez, D.; Chami, M. Spectral variations of light scattering by marine particles in coastal waters, from visible to near infrared. Limnology and Oceanography 2009, 54, 1257-1271.

79. Sun, D.; Li, Y.M.; Wang, Q.; Le, C.F.; Lyv, H.; Huang, C. Specific inherent optical quantities of complex turbid inland waters from the perspective of water classification. Photochemical and Photobiological Sciences 2012, 11(8), 1299-1312.

80. Barnard, A. H.; Pegau, W. S.; Zaneveld, J. R. V. Global relationships of the inherent optical properties of the oceans. Journal of Geophysical Research-Oceans 1998, 103, 2495524968.

81. Stramski, D.; Bricaud, A.; Morel, A. Modeling the inherent optical properties of the ocean based on the detailed composition of the planktonic community. Applied Optics 2001, 40, 2929-2945.

82. Doxaran, D.; Babin, M.; Leymarie, E. Near-infrared light scattering by particles in coastal waters. Optics Express 2007, 15, 12834-12849.

\section{Figure Caption}

Figure 1. Reflectance spectrum measured with ASD spectrometer in Geist Reservior, USA. Vertical dased lines represent wavelength locations at which optically active compoenents are spectrally diagnostic, and their spectral features are described in text.

Figure 2. Correlations between the measured and estimated PC concentrations by (a) FBBM, (b) $\mathrm{BR}_{645 / 620}$, (c) TBM, (d) PCI for the in situ data collected in 2010 for Eagle Creek $(\mathrm{n}=60)$, Geist $(\mathrm{n}=37)$ and Morse $(\mathrm{n}=54)$ reservoirs, central Indiana, USA with $n$ being the number of water 
samples. These models were calibrated against 187 samples collected from Lake IJsselmeer (LIJ), and shown here are the validation results. The solid lines are the 1:1 lines. (adapted from Liu et al. 2017).

Figure 3. Correlations between the measured and estimated PC concentrations by (a) EIIMIW, (b) NBR for the in situ data collected in 2005, 2006, 2007, and 2008 for Eagle Creek, Geist and Morse reservoirs. The validation results were obtained by the models calibrated against data collated in 2010 for the same water bodies, and are shown in logarithmic scale for clarity. The solid line and dash line are regression and 1:1 correlation, respectively. (adapted from Li et al. 2015).

Table 1: Site conditions for developing representative PC models and their performance description

\begin{tabular}{cccccc}
\hline Model & Sampling Site & PC $(\mu \mathrm{g} / \mathrm{L})$ Range & $\mathbf{R}^{2}$ & $\begin{array}{l}\text { RMSE }(\mu \mathrm{g} / \mathrm{L}) \\
\text { or rRMSE }(\%)\end{array}$ & Reference \\
\hline $\mathrm{BR}_{709 / 620}$ & Lab culture & - & 0.95 & 6.35 & {$[25]$} \\
\hline $\mathrm{BR}_{700 / 600}$ & Lab culture & $506-273883^{*}$ & $0.94^{\dagger}$ & $19957^{\dagger}$ & {$[26]$} \\
\hline $\mathrm{BR}_{650 / 625}$ & Carter Lake, USA & $0-530$ & 0.612 & - & {$[8]$} \\
\hline MRBI & Lakes & $7-130$ & 0.99 & 2.34 & {$[3]$} \\
\hline $\mathrm{SSA}$ & Bear Lake & - & - & - & {$[30]$} \\
\hline PCI & Lake Taihu & $1-300$ & 0.64 & $85.4 \%$ & {$[33]$} \\
\hline TBM & $\begin{array}{c}\text { Lake Loch Leven and } \\
\text { Esthwaite Water, UK }\end{array}$ & $0-93.7$ & 0.92 & 2.65 & {$[35]$} \\
\hline DTBB & $\begin{array}{c}\text { Eagle Creek and Geist } \\
\text { reservoirs, USA }\end{array}$ & $6.6-140$ & 0.857 & $31.4 \%$ & {$[37]$} \\
\hline FBM & Lake Taihu, China & $2.67-107.67$ & 0.86 & 4.83 & {$[38]$} \\
\hline
\end{tabular}




\begin{tabular}{cccccc}
\hline FBBM & $\begin{array}{c}\text { Lakes and reservoirs in } \\
\text { China, The Netherlands and } \\
\text { USA }\end{array}$ & $0-710.28$ & 0.73 & 27.69 & {$[39]$} \\
\hline NBR & $\begin{array}{c}\text { LakesLoosdrecht and } \\
\text { IJsselmeer in The } \\
\text { Netherlands }\end{array}$ & $0.8-79.8$ & 0.94 & 6.5 & {$[11]$} \\
\hline QAA $_{\text {pc }}$ & Aquaculture ponds, USA & $68.13-3032.47$ & 0.99 & $30.7 \%$ & {$[44]$} \\
\hline EIIMIW & $\begin{array}{c}\text { Eagle Creek, Geist and } \\
\text { Morse reservoirs, USA }\end{array}$ & $0.73-370.95$ & $0.81^{\dagger}$ & $33.6 \%^{\dagger}$ & {$[46]$} \\
\hline
\end{tabular}

*: cyanobacteria cell number per $\mathrm{mL} ;{ }^{\dagger}$ : results for validation -: unavailable data

Table 2: List of symbols and acronyms.

\begin{tabular}{|c|c|c|}
\hline $\begin{array}{l}\text { Symbol/ } \\
\text { acronym }\end{array}$ & Description & Units \\
\hline$b_{b}(\lambda)$ & Total backscattering coefficients at wavelength $\lambda$ & $\mathrm{m}^{-1}$ \\
\hline$b_{b p}(\lambda)$ & Backscattering coefficients of particles at wavelength $\lambda$ & $m^{-1}$ \\
\hline$a_{p c}^{*}(\lambda)$ & PC specific absorption coefficients at wavelength $\lambda$ & $\mathrm{m}^{2}(\mathrm{mg} \mathrm{PC})^{-1}$ \\
\hline$a_{i}(\lambda)$ & $\begin{array}{l}\text { Absorption coefficients of compound } i \text { at wavelength } \lambda \text {. Subscripts } \\
\text { used: } t-w=\text { non-water; } p h y=\text { phytoplankton; } c d m=\text { colored detritus } \\
\text { matter; } p c=\text { phycocyanin; } p h-p c=\text { phytoplankton pigments } \\
\text { excluding phycocyanin; } c d m+p c=\text { colored detritus matter plus } \\
\text { phycocyanin. }\end{array}$ & $\mathrm{m}^{-1}$ \\
\hline$S_{c d m}$ & Exponential slope of $a_{c d m}(\lambda) ; a_{c d m}(\lambda)=a_{c d m}\left(\lambda_{0}\right) \exp \left[-S_{c d m} \times\left(\lambda-\lambda_{0}\right)\right]$ & $\mathrm{nm}^{-1}$ \\
\hline$R_{r s}(\lambda)$ & Remote sensing reflectance above water surface at wavelength $\lambda$ & $\mathrm{sr}^{-1}$ \\
\hline$r_{r s}(\lambda)$ & Remote sensing reflectance below water surface at wavelength $\lambda$ & $\mathrm{sr}^{-1}$ \\
\hline$\eta$ & Linear interpolation weight & - \\
\hline nLw & Normalized leaving water radiance & $\begin{array}{c}\mathrm{mW} / \mathrm{cm}^{2} / \mu \mathrm{m} / \\
\mathrm{sr}\end{array}$ \\
\hline$[\mathrm{PC}]$ & Phycocyanin (concentration) & $\mathrm{mg} \mathrm{m}^{-3}$ \\
\hline$[\mathrm{Chl}-a]$ & Chlorophyll-a concentration & $\mathrm{mg} \mathrm{m}^{-3}$ \\
\hline [TSM] & Total suspended matter concentration & $\mathrm{g} \mathrm{m}^{-3}$ \\
\hline [NAP] & Non-algal particles & $\mathrm{g} \mathrm{m}^{-3}$ \\
\hline $\mathrm{CDOM}$ & Colored dissolved organic matter & - \\
\hline CDM & Colored detritus matter; CDOM and NAP combined & - \\
\hline rRMSE & Relative root mean square error & - \\
\hline AOP & Apparent optical properties & - \\
\hline IOP & Inherent optical properties & - \\
\hline $\mathrm{OAC}$ & Optically active constituents & - \\
\hline
\end{tabular}




$\begin{array}{cll}\text { BR } & \text { Band ratio } & - \\ \text { MRBI } & \text { Midpoint reflectance baseline index } & - \\ \text { SSA } & \text { Spectral shape algorithm } & - \\ \text { PCI } & \text { Phycocyanin index } & - \\ \text { TBM } & \text { Three band model } & - \\ \text { DTBB } & \text { Double three band baseline } & - \\ \text { FBM } & \text { Four band model } & - \\ \text { FBBM } & \text { Four band baseline model } & - \\ \text { NBR } & \text { Nested band ratio } & - \\ \text { QAApc } & \text { Quasi-analytical algorithms for PC } & - \\ \text { EIIMIW } & \text { Extension of IOP inversion model for inland waters } & - \\ \text { MERIS } & & - \\ \text { OLCI } & \text { Ocean and land color imager } & - \\ \text { AISA } & \text { Airborne imaging spectrometer for applications } & - \\ \text { EnMap } & \text { Environmental mapping and analysis program } & - \\ \text { HyspIRI } & \text { Hyperspectral infra-red imager } & - \\ \text { PRISMA } & \text { PRecursore IperSpettrale della Missione Applicativa } & \end{array}$


Table 3: A summary of empirical algorithms for PC estimation

\begin{tabular}{lcc}
\hline & Spectral Predictor & Reference \\
\hline $\mathrm{BR}_{709 / 620}$ & $R_{x}(709) / R_{x}(620)$ & {$[25]$} \\
$\mathrm{BR}_{700 / 600}$ & $R_{x}(700) / R_{x}(600)$ & {$[26]$} \\
$\mathrm{BR}_{650 / 625}$ & $R_{r s}(650) / R_{r s}(625)$ & {$[8]$} \\
$\mathrm{MRBI}$ & $0.5\left(R_{r s}(665)+R_{r s}(560)\right)-R_{r s}(624)$ & {$[3]$} \\
$\mathrm{SSA}(681)$ & $n L w(681)-(n L w(709)-n L w(665))\left(\frac{681-665}{709-665}\right)$ & {$[30]$} \\
& $-n L w(665)$ & {$[33]$} \\
$\mathrm{PCI}(620)$ & $R_{r s}(560)+\left(R_{r s}(665)-R_{r s}(560)\right)\left(\frac{620-560}{665-560}\right)$ & \\
\hline
\end{tabular}

Table 4: A summary of semi-empirical algorithms for PC estimation

\begin{tabular}{lcc}
\hline Model & Spectral Predictor & Reference \\
\hline TBM & $\left(R_{r s}^{-1}\left(\lambda_{1}\right)-R_{r s}^{-1}\left(\lambda_{2}\right)\right) \times R_{r s}\left(\lambda_{3}\right)$ & {$[35]$} \\
DTBB & $0.5 \times\left\{\left[a_{w}(725)+b_{b}(725)\right](R 31+R 32)-2 \times a_{w}(624)+a_{w}(600)+a_{w}(648)\right\}$ & {$[37]$} \\
FBM & $\left(R_{r s}\left(\lambda_{1}\right)^{-1}-R_{r s}\left(\lambda_{2}\right)^{-1}\right) /\left(R_{r s}\left(\lambda_{4}\right)^{-1}-R_{r s}\left(\lambda_{3}\right)^{-1}\right)$ & {$[38]$} \\
FBBM & $\left(R_{r s}\left(\lambda_{1}\right)^{-1}-\eta_{\lambda_{3}}^{\lambda_{2}}\left(\lambda_{1}\right) R_{r s}\left(\lambda_{2}\right)^{-1}-\left(1-\eta_{\lambda_{3}}^{\lambda_{2}}\left(\lambda_{1}\right)\right) R_{r s}\left(\lambda_{3}\right)^{-1}\right) R_{r s}\left(\lambda_{4}\right)$ &
\end{tabular}


Table 5: A summary of semi-analytical algorithms for PC estimation

\begin{tabular}{|c|c|c|}
\hline Model & Spectral Predictor & Reference \\
\hline NBR & $\begin{aligned} a_{c h l-a}(665)= & \left\{\left[R_{r s}(709) / R_{r s}(665) \times\left(a_{w}(709)+b_{b}\right)\right.\right. \\
& \left.\left.-b_{b}-a_{w}(665)\right] \times \gamma^{-1}\right\} \\
a_{p h y}(620)= & \left(\left\{R_{r s}(709) / R_{r s}(620) \times\left[a_{w}(709)+b_{b}\right]\right\}\right. \\
& \left.-b_{b}-a_{w}(620)\right) \times \delta^{-1} \\
a_{P C}(620)= & \left(\left\{R_{r s}(709) / R_{r s}(620) \times\left[a_{w}(709)+b_{b}\right]\right\}-b_{b}\right. \\
& \left.-a_{w}(620)\right) \times \delta^{-1}-\varepsilon \times a_{C h l a}(665)\end{aligned}$ & [11] \\
\hline $\mathrm{QAA}_{\mathrm{pc}}$ & $\begin{array}{c}\text { QAA to derive } a_{p h y}(\lambda) \\
a_{p h y}(665)=a_{c h l-a}(665)+a_{P C}(665) \\
a_{p h y}(620)=a_{c h l-a}(620)+a_{P C}(620) \\
a_{p c}(620)=\left(a_{p h y}(620) \psi_{1}-a_{p h y}(665)\right) /\left(\psi_{1}-\psi_{2}\right)\end{array}$ & [44] \\
\hline EIIMIW & $\begin{array}{c}r_{r s}(\lambda)=R_{r s}(\lambda) /\left(0.52+1.7 R_{r s}(\lambda)\right) \\
b_{b}(778)=r_{r s}(778) a_{w}(778) /\left(0.082-r_{r s}(778)\right)\end{array}$ & [46] \\
\hline $\begin{array}{l}\text { Deviation of } \\
\text { non-water } \\
\text { OACs'absorption }\end{array}$ & $\begin{array}{r}Y=2.0\left(1-1.2 \exp \left(-0.9 r_{r s}(443) / r_{r s}(560)\right)\right) \\
b_{b p}(560)=\left(b_{p}(778)-b_{w}(778)\right) / 0.1798^{Y} \\
b_{b}(\lambda)=b_{b p}(560)(560 / \lambda)^{Y}+b_{b w}(778) \\
a_{t-w}(\lambda)=r_{r s}(709) b_{b}(\lambda)\left(a_{w}(709)+b_{b}(709)\right) \\
\quad /\left(r_{r s}(\lambda) b_{b}(709)\right)-b_{b}(\lambda)-a_{w}(\lambda)\end{array}$ & \\
\hline $\begin{array}{l}\text { Derivation of } \\
\text { non-algal particle } \\
\text { and CDOM } \\
\text { absorption with } \\
\text { and without PC }\end{array}$ & $\begin{array}{c}a_{p h y-P C}(\lambda)=1.1872 C 1(\lambda) a_{t-w}(665)+C 2(\lambda) \\
a_{c d m+P C}(\lambda)=a_{t-w}(\lambda)-a_{p h y-P C}(\lambda) \\
a_{c d m}(\lambda)=a_{c d m}(412) \exp \left(-\ln \left(\frac{a_{c d m}(412)}{a_{c d m}(510)}\right)(\lambda\right. \\
-412) / 98) \\
\text { where } a_{c d m}(412)=a_{c d m+P C}(412), a_{c d m}(510)= \\
a_{c d m+P C}(510), \text { and } a_{c d m}(709) \text { should be forced to be zero } \\
a_{P C}(620)=a_{c d m+P C}(620)-a_{c d m}(620)\end{array}$ & \\
\hline
\end{tabular}




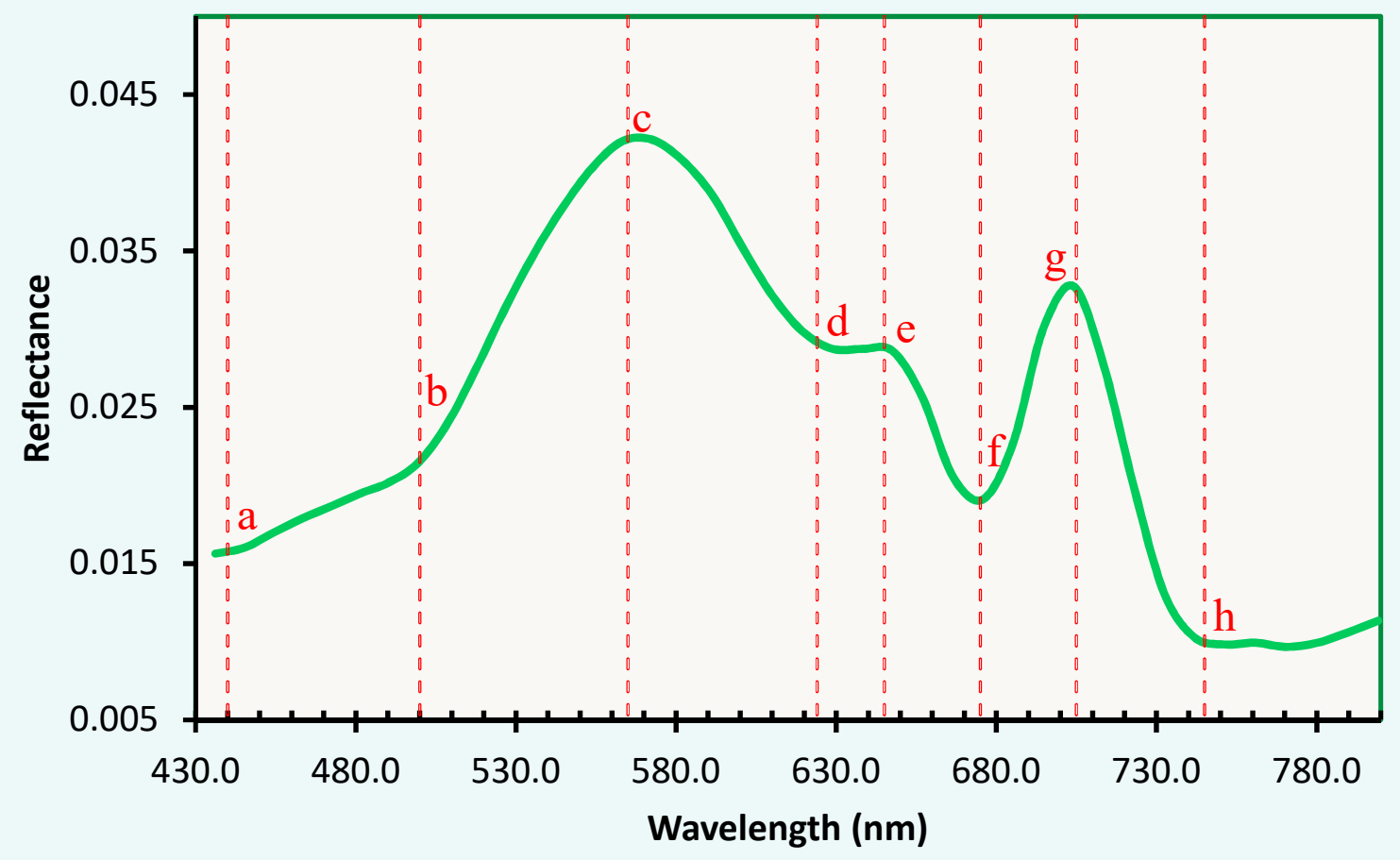

Figure 1. Reflectance spectrum measured with ASD spectrometer in Geist Reservior, USA.

Vertical dased lines represent wavelength locations at which optically active compoenents are spectrally diagnostic, and their spectral features are described in text. 

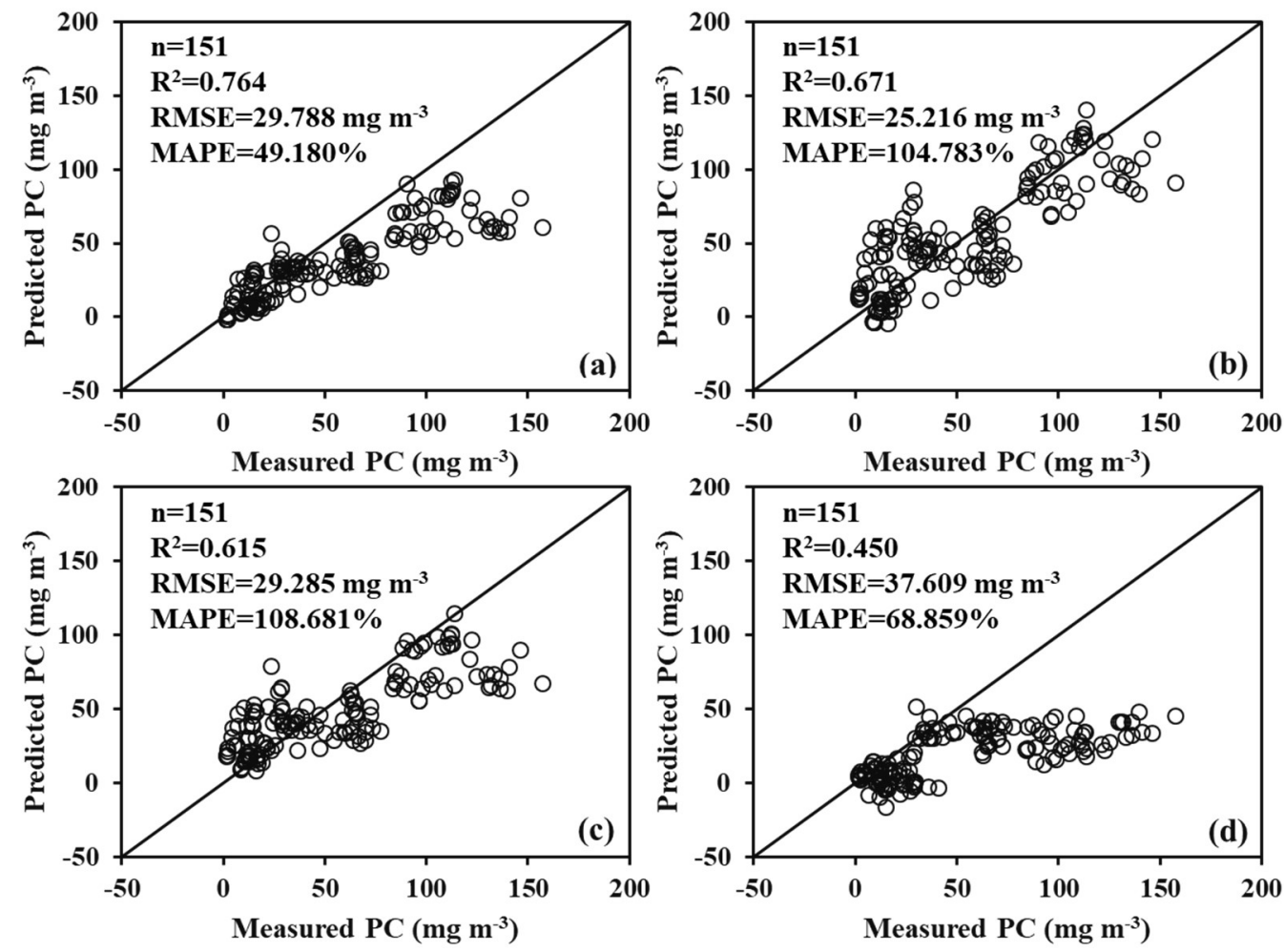

Figure 2. Correlations between the measured and estimated PC concentrations by (a) FBBM, (b) $\mathrm{BR}_{645 / 620}$, (c) TBM, (d) PCI for the in situ data collected in 2010 for Eagle Creek ( $\left.\mathrm{n}=60\right)$, Geist $(\mathrm{n}=37)$ and Morse $(\mathrm{n}=54)$ reservoirs, central Indiana, USA with $n$ being the number of water samples. These models were calibrated against 187 samples collected from Lake IJsselmeer (LIJ), and shown here are the validation results. The solid lines are the 1:1 lines. (adapted from Liu et al. 2017). 

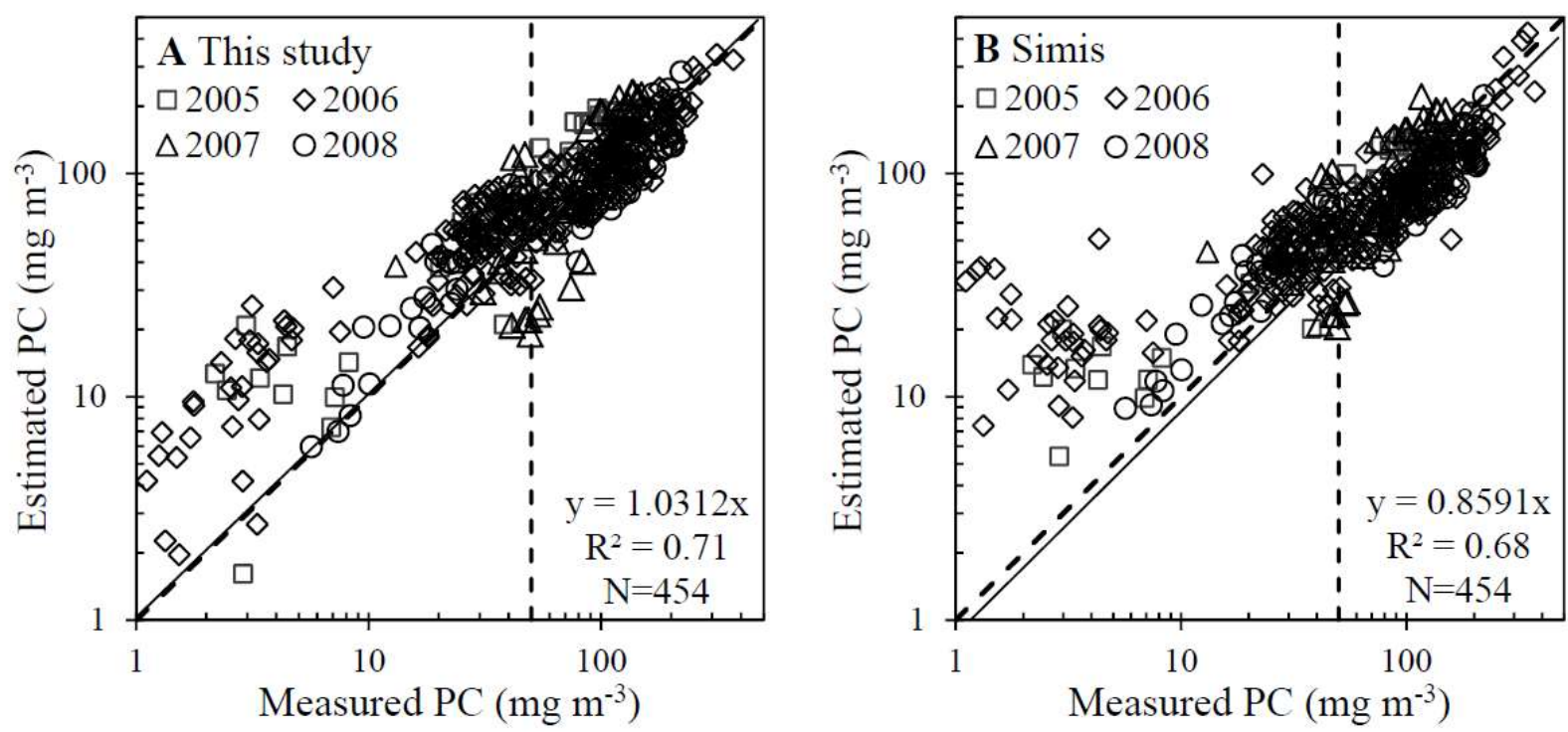

Figure 3. Correlations between the measured and estimated PC concentrations by (a) EIIMIW, (b) NBR for the in situ data collected in 2005, 2006, 2007, and 2008 for Eagle Creek, Geist and Morse reservoirs. The validation results were obtained by the models calibrated against data collated in 2010 for the same water bodies, and are shown in logarithmic scale for clarity. The solid line and dash line are regression and 1:1 correlation, respectively. (adapted from Li et al. 2015). 